\title{
A relação entre virtude e felicidade em Sócrates
}

\section{The relation between virtue and happiness in socrates}

\author{
Aldo Dinucci ${ }^{1}$ \\ Universidade Federal de Sergipe
}

\begin{abstract}
RESUMO: Neste artigo, analisamos três hipóteses sobre a relação entre virtude e felicidade em Sócrates. Em primeiro lugar, a tese de Irwin (1995), que afirma uma relação instrumental entre virtude e felicidade; em segundo, a tese de Vlastos (1994), que afirma uma relação parcialmente constitutiva e, finalmente, após apontarmos contradições nestas, assumimos a tese da relação de identidade entre virtude e felicidade em Sócrates.
\end{abstract}

Palavras-chave: filosofia clássica, ética, Sócrates, Socratismo.

ABSTRACT: In this paper we analyze three hypotheses about the relation between virtue and happiness in Socrates. In the first place, Irwin's thesis (1995) that asserts an instrumental relation between virtue and happiness; second, Vlastos' thesis (1994) that asserts a partially constitutive relation and, finally, after discussing the contradictions in those theses, we stated the identity relation thesis between virtue and happiness in Socrates.

Key words: classical philosophy, ethics, Socrates, Socratism.

\section{Introdução}

Os principais comentadores do pensamento socrático discordam quanto ao status da relação entre virtude e felicidade em Sócrates: ora sugerem que há uma relação instrumental entre ambas (a virtude é apenas um meio para atingir a felicidade); ora apontam uma relação parcialmente constitutiva (a virtude é um entre outros componentes da felicidade). O objetivo deste artigo é apresentar criticamente duas das mais importantes interpretações da atualidade sobre tal relação, quais

1 Professor adjunto do Departamento de Filosofia da Universidade Federal de Sergipe. Endereço: Avenida Marechal Rondon, sem número, Jardim Rosa Elze, Cidade Universitária Professor José Aloísio de Campos. São Cristovão, SE. E-mail: aldodinucci@ufs.br. 
sejam, a de Irwin (1995), que defende a primeira tese; e a de Vlastos (1994), que defende a segunda. Após esses esclarecimentos, pretendemos chegar a um veredicto próprio quanto à questão, que é, como veremos, a afirmação de uma relação de identidade entre virtude e felicidade em Sócrates.

Há passagens nos primeiros diálogos socráticos ${ }^{2}$ que parecem apoiar teses diferentes sobre a relação entre virtude e felicidade no pensamento de Sócrates. Citemos, em primeiro lugar, o argumento do Protágoras, por meio do qual Sócrates sustenta uma tese hedonista e defende que a virtude não é senão um instrumento para se atingir a felicidade (Platão, 1990, 353 b - 354 e). O argumento aí apresentado pode ser formalizado da seguinte maneira:

(i) Nós cremos que $x$ é melhor que y se, e apenas se, nós também cremos que $x$ produz mais prazer que $y$;

(ii) Se nós cremos que $x$ é melhor que $y$, nós cremos que isso é assim porque cremos que $x$ produz mais prazer que $y$;

(iii) Nós buscamos o prazer como o bem e evitamos a dor como o mal.

Assim, esse argumento, aparentemente, mostra que, para Sócrates, a virtude nada é senão um meio para se obter as coisas boas (prazerosas) e, consequentemente, a felicidade. Tratamos desse argumento em duas oportunidades adiante: quando analisamos a tese de Irwin (1995), na próxima seção, e quando consideramos o contexto em que tal argumento se desenvolve, na última seção.

Uma passagem do Eutidemo, por sua vez, mostra-se como sustentação da ideia de que a sabedoria que torna o homem virtuoso é o único bem para o homem e que sua posse implica a felicidade; dessa forma, chega-se à tese da identidade entre virtude e felicidade. Tal argumento pode ser assim resumido:

(i) A felicidade não requer boa fortuna adicionada à virtude (Platão, 1990, 279 c 4- 280 a 8). Essa primeira premissa é defendida pelo seguinte argumento: (a) em todos os casos, o homem sábio é mais bem-sucedido que o ignorante (Platão, 1990, 80 a 4- 5); (b) a sabedoria genuína (a techne moral socrática) nunca erra, é sempre bem-sucedida (Platão, 1990, 280 a 7- 8); logo, (c) a sabedoria é vista como condição necessária e suficiente para a felicidade.

(ii) A sabedoria é necessária e suficiente para o uso correto e bem-sucedido das coisas (Platão, 1990, 280 b 1- 281 b 4). Essa premissa é defendida pelo seguinte argumento: (a) é possível utilizar bem ou mal as coisas (Platão, 1990, 280 b 7- c 3; 280 d 7- 281 a 1); (b) o uso correto delas é necessário e suficiente para a felicidade (Platão, 1990, 280 d- 281 e 1); (c) a sabedoria é necessária e suficiente para esse uso correto (Platão, 1990, 281 a 1- b 2); logo, (d) a sabedoria é necessária e suficiente para a felicidade (Platão, 1990, 281 b 2 - 4).

(iii) A sabedoria é o único bem (Platão, 1990, 281 b 4- e 5). Essa conclusão é defendida com base no seguinte argumento: (a) todo bem é pior que seu contrário, se usado sem sabedoria, mas é melhor que seu contrário, se usado com sabedoria (Platão, 1990, 281 d 6- 8); logo, (b) tudo o que é dito um bem que não seja a sabedoria não é em si mesmo nem bom nem mau (Platão, 1990, 281 e 3- 4), portanto (c) nenhum deles é bom ou é mau (Platão, 1990, 281 e 3-4), e (d) a sabedoria é o único bem e a ignorância é o único mal (Platão, 1990, 281 e 4- 5).

2 Estes são os primeiros diálogos de Platão: Apologia, Carmides, Criton, Eutífron, Eutidemo, Górgias, Hípias Menor, Ion, Lísias, Laques, Protágoras, Livro 1 da República e primeira parte do Mênon. Também são chamados de aporéticos (pois frequentemente terminam em aporia). 
Outras passagens dos diálogos socráticos parecem reafirmar essa tese, como na Apologia (Platão, 1995, 41 c 8- d 2), na República (Platão, 1999, I, 335 c 1- 7) e no Górgias (Platão, 1991, 470 e 4- 11; 507 b 8- c 7). Ao final deste artigo, é esclarecido o argumento que defende tal tese.

Outras passagens nos primeiros diálogos parecem indicar que Sócrates reconhecia outros bens que não somente a virtude. Como exemplo, indicamos três dessas passagens na Apologia: a primeira, na qual Sócrates conta a riqueza e outras coisas como bens (Platão, 1995, 30 b 2-4); outra, na qual Sócrates repreende os que dão mais valor ao que é inferior, deixando de lado o cultivo da virtude (Platão, 1995, 29 e5-30 a2); e, por fim, uma terceira, na qual Sócrates diz que todas as coisas boas para os homens advêm da sabedoria. Tais passagens parecem indicar que a relação entre virtude e felicidade é parcialmente constitutiva e que há outros elementos que constituem a felicidade humana, além da sabedoria. Analisamos essas passagens quando abordamos a interpretação de Vlastos (1994), na segunda seção do presente trabalho.

\section{Irwin e a Tese da Instrumentalidade da Virtude}

Segundo a tese de Irwin (1995), a virtude é, para Sócrates, causa da felicidade, mas não um componente dela. Para Irwin (1995, p. 53), a posição eudaimonista socrática pressupõe três princípios básicos para a ação: (i) em todas as ações racionais, buscamos nossa própria felicidade; (ii) buscamos a felicidade por conta dela própria; (ii) seja o que for que busquemos racionalmente, nós o buscamos em prol da felicidade.

Irwin (1995) argumenta que, no Lísias, Sócrates faz uma distinção entre objetos secundários e primários do amor, declarando que apenas os objetos primários do amor são amados por conta de si próprios e que apenas o que é amado verdadeiramente é amado por conta de si mesmo e não em vista de algo mais (Cf. Platão, 1991, 219 c 1- d 5; 220 a 6- b 5; 220 b 4- 5). A série das coisas amadas deve ser necessariamente finita, e devemos chegar a um objeto de amor que é amado por ele mesmo e pelo qual amamos as demais coisas (Cf. Platão, 1991, 219 c 5- d 2). Nesses diálogos, entretanto, Sócrates não diz que o objeto primário seja a felicidade. No supracitado argumento do Eutidemo (Cf. Platão, 1999, 279 a14b3), reflete Irwin (1995), a felicidade é vista como o objeto que é desejado por si mesmo: outros bens só são buscados em vista da felicidade. Sócrates, argumenta Irwin (1995, p. 54), "supõe que a felicidade seja o único fim que buscamos [...] e o único que não buscamos em vista de outra coisa". Segundo esse comentador, outros diálogos confirmam a posição apresentada no Eutidemo: mesmo na Apologia (Cf. Platão, 1995, 28 b 5- 9), em que Sócrates afirma que a ação virtuosa deve ser sempre preferida, ele o faz não supondo que a virtude seja um fim em si, mas que a virtude é desejada em prol da felicidade, já que viver bem é o mesmo que viver de modo justo, isto é, virtuoso, como é dito no Criton (Cf. Platão, 1995, 48 b 4- 10).

Irwin (1995) concorda que, segundo o argumento do Eutidemo, que sintetizamos acima, a sabedoria é, para Sócrates, o único bem; e a ignorância, o único mal. Entretanto, esse autor aponta outras passagens dos primeiros diálogos que parecem endossar a tese segundo a qual há bens intermediários, como na supracitada passagem da Apologia (Cf. Platão, 1995, 30 b 2- 4), em que Sócrates afirma que a virtude é a fonte da riqueza e de outros bens. Irwin (1995, p. 59) reconhece que essa passagem pode ser compreendida, também, como indicativa de que a sabedoria é, de fato, a fonte de todos os bens. Tal compreensão pressupõe que a sabedoria seja capaz de utilizar aquilo que o senso comum considera como bens para não interferir na própria felicidade ou virtude. Assim, para Irwin (1995), Só- 
crates, também na Apologia, está comprometido com a visão segundo a qual a sabedoria é o único bem.

Irwin (1995) compreende as afirmações de Sócrates de que a virtude seja suficiente para a felicidade, como é afirmado na Apologia (Platão, 1995, 30 c 6- d 5, 41 c 8- d 2), no Criton (Platão, 1995, 48 b 8- 9) e no Carmides (Platão, 2002, 173 d 3- 5; 174 b 11- c 3.), noção que significa que o homem sábio sacrifica outros bens, se isso for preciso, para se manter virtuoso e, por consequência, feliz:

Sócrates interpreta seu pressuposto a partir de seu ponto de vista eudaimonista. Em sua visão, a ação racional almeja a felicidade do próprio agente, e agentes bem informados têm crenças verdadeiras sobre o que contribui para sua própria felicidade. Já que pessoas virtuosas que sacrificam outros bens pela virtude estão tomando a decisão certa e não são enganados pela ignorância, nós devemos, de acordo com Sócrates, concordar que elas estão fazendo o que é o melhor para si mesmas. Segue-se que as pessoas virtuosas devem crer corretamente que sua ação virtuosa promove sua própria felicidade melhor que o faria qualquer outra ação (Irwin, 1995, p. 59, grifo nosso).

Entretanto, se o argumento do Eutidemo claramente assevera a inexistência de outros bens senão a sabedoria, então não faz sentido falar de sacrificar outros bens. $\mathrm{O}$ argumento do Eutidemo claramente atesta que as demais coisas são indiferentes, quer dizer, se usadas com sabedoria, tornam-se bens; se, com ignorância, males. Isso significa que elas não são, por si mesmas, nem bens nem males, mas tão somente meios pelos quais a sabedoria e a ignorância podem se expressar; são matéria para os atos virtuosos ou contrários à virtude, e não têm valor algum. Assim, a ação virtuosa não é melhor que outras ações, mas é a única boa alternativa. As coisas não podem, com exceção da sabedoria, ser boas ou más em si mesmas em nenhum sentido. Para Sócrates, quando dizemos que algo é bom, é bom em relação à sabedoria (pela qual se faz bom uso daquela). No entanto, o uso que Irwin (1995) faz do termo "bem" tende a obscurecer esta concepção de ação virtuosa, a qual leva a confundir o que Sócrates cuidadosamente distingue. Além disso, faz parecer que tais coisas sejam intrinsecamente boas. Assim, não há porque concordar com Irwin (1995). Para esse pensador, tal argumentação socrática sustenta apenas uma tese comparativa, segundo a qual a virtude contribui para a felicidade mais do que qualquer outra coisa, mas não a tese da suficiência, segundo a qual a virtude é suficiente para a felicidade.

Irwin (1995) procura, ainda, provar que Sócrates, implicitamente, aceita que os bens não são partes da felicidade, mas meios para atingi-la, e isso constitui a tese instrumentalista da relação entre virtude e felicidade no pensamento socrático. O autor (1995) apresenta algumas passagens dos primeiros diálogos para apoiar essa tese. A primeira é do Lísias:

Embora digamos que muitas coisas são amadas por alguma coisa que é amada, nós evidentemente estamos falando de modo inapropriado ao dizer isto. Parece que a coisa que é realmente amada é aquela na qual todas as coisas chamadas amadas chegam ao fim [...] Então o que é verdadeiramente amado não é amado por nenhuma outra coisa (Platão, 1991, 220 a7- b5).

Diante dessa passagem, o estudioso argumenta que, se aceitarmos o que é dito como um princípio geral, "então não podemos dizer que a virtude seja um constituinte da felicidade; pois se fosse [...] ela deveria ser escolhida tanto por causa de si mesma quanto pela felicidade" (Irwin, 1995, p. 67). O autor denomina tal concepção da virtude como meio para atingir a felicidade de "princípio instrumental 
dos bens não finais" (Irwin, 1995, p.67). Porém, mais uma vez devemos lembrar que o argumento do Eutidemo atesta claramente que, para Sócrates, a virtude é o único bem e a causa da felicidade, independentemente de algo exterior. Aparentemente, a virtude é escolhida por Sócrates, simultaneamente por si mesma e pela felicidade, pois sua posse já é a felicidade na medida em que com ela se faz bom uso de todas as coisas ou na medida em que permite ao homem bem viver.

Irwin (1995, p. 81 ss.) responde à questão "Em que consiste a felicidade para Sócrates?" com auxílio do supracitado argumento do Protágoras, concluindo que "Na visão de Sócrates, nós consideramos as coisas como boas porque supomos que elas são prazerosas, mas não as consideramos como prazerosas porque são boas" (Irwin, 1995, p. 82). A partir disso, o autor afirma que (i) a techne socrática é vista como uma arte hedonista de medir, pela qual o homem busca o curso de ação que o conduz à obtenção do máximo de prazer e, logo, do maior bem e da mais intensa felicidade (Irwin, 1995, p. 84), e (ii) a felicidade é vista como a maior quantidade de prazer possível e disponível ao homem, prazer que é o produto da techne hedonista.

Irwin (1995), entrementes, reconhece que o comprometimento de Sócrates com a virtude e o bem viver parece desmentir a adesão socrática a tal tese instrumentalista (Irwin, 1995, p. 77), observando que, embora não seja possível provar que Sócrates cria nessa tese, bastaria provar que ele não rejeitaria tal tese. Assim, podemos dizer que a interpretação de Irwin (1995) se apoia sobretudo no argumento do Protágoras, que é, de fato, a única instância nos primeiros diálogos que parece apoiar a interpretação desse comentador. Voltamos ao argumento do Protágoras no final deste artigo.

\section{Vlastos (1994) e a relação parcialmente constitutiva entre virtude e felicidade}

Vlastos (1994), por sua vez, tem a intenção de provar que a tese instrumentalista está em contradição com as ideias expressas por Sócrates. Esse comentador defende o "princípio socrático da soberania da virtude", segundo o qual, cada vez que nos fosse necessário escolher entre duas ações, uma que consideramos justa e outra que consideramos injustas, "deliberar mais ainda seria inútil, pois nenhum dos bens não morais que poderíamos esperar ganhar [...] compensaria a perda de um bem moral" (Vlastos, 1994, p. 291). Tal princípio se apresenta enunciado duas vezes na Apologia:

Homem, tu estás errado se pensas que um homem no qual há mesmo o menor mérito deva considerar (hupologizesthai) o perigo de vida ou morte, e não considerar apenas se, quando ele faz algo, o que ele faz é justo ou injusto, se é o ato de um homem bom ou de um homem mau (Platão, 1995, 28 b 5- 9).

E mais adiante:

Aqui está a verdade sobre a questão, homens de Atenas; onde quer que um homem pare, pensando que é melhor estar ali [...] é ali [...] que ele deve permanecer, sem considerar a morte nem qualquer outra coisa que seja diante do risco de agir de modo desonroso (Platão, 1995, 28 d 6- 10).

Bem como no Criton, em que Sócrates vê a possibilidade de fuga como uma ação injusta: 
A única coisa que devemos considerar é [...] se agiremos com justiça [...] ou se, em verdade, cometeremos uma injustiça [...] E se se tornasse evidente que esta ação é injusta, então o fato de que permanecendo aqui eu devesse morrer ou sofrer o que quer que seja, esse fato não deveria ser considerado (hupologizesthai) diante do risco de agir de modo injusto (Platão, 1995, 48 c 6- d 5).

Como é dito no Górgias (Platão, 1991, 507 c) As virtudes, quando possuídas por um homem, tornam-no bom e, logo, feliz. Ora, o princípio da soberania da virtude explica a razão pela qual Sócrates afirma que não se deve jamais cometer um injustiça e que não se deve jamais responder a uma injustiça com outra injustiça (esta é a recusa socrática da Lei de Talião).

Vlastos (1994), então, empreende a busca do que considera fundamento do princípio da soberania da virtude, encontrando-o no Criton:

A partir dos pontos sobre os quais estamos de acordo - diz Sócrates, refletindo sobre a possibilidade da fuga diante da pena de morte proclamada por seus concidadãos - , consideremos isto: seria justo ou injusto romper essa ligação sem o consentimento dos atenienses? Se for justo, nós o faremos, se não, não o faremos (Platão, 1995, 48 b 11- c 2).

Essa passagem evidencia que a escolha é feita unicamente a partir de um único critério: a consideração do caráter justo ou injusto da ação a ser executada. Mas por que a escolha deve seguir esse critério? No próprio Criton, Sócrates oferece uma resposta:

Sócrates: Manteremos ainda, sim ou não, que devemos conceder o mais alto valor não ao fato de viver (zen), mas ao fato de viver bem (eu zen)?

Criton: Manteremos isso.

Sócrates: E que viver bem e viver de modo justo (dikaios) e bom (kalos) são a mesma coisa? Manteremos isso ou não?

Criton: Nós o manteremos (Platão, 1995, 48 b 11- c 2).

Em vista disso, a ação justa deve ser sempre preferida, pois viver de modo justo é o mesmo que bem viver. Vlastos (1994), após tais considerações, busca uma alternativa à tese instrumentalista: esta alternativa, reflete o comentador, deve resgatar a importância no pensamento socrático do cultivo da virtude e da valorização do bem viver em relação ao mero viver, pontos que, como o próprio Irwin (1995) reconhece, perdem força e sentido na interpretação instrumentalista.

Quanto à relação de identidade entre virtude e felicidade no pensamento socrático, Vlastos (1994) tenta mostrar que ela não é consistente com algumas passagens dos diálogos da juventude de Platão. Vlastos (1994) - e nisso se identifica com Irwin (1995) - defende a tese segundo a qual a felicidade, em Sócrates, admite outros componentes além da virtude, embora esta mantenha seu lugar soberano no que concerne à felicidade. A virtude é necessária e suficiente para a felicidade, porém esta aceita outros componentes de menor importância (Vlastos, 1994, p. 298), o que significa que "uma pessoa virtuosa seria feliz, sem consideração aos bens não morais que ela pudesse possuir, mas mais feliz com um ou muitos desses bens" (Vlastos, 1994, p. 298, nota 64). Este autor chama essa concepção pluricomponencial da felicidade de "tese da suficiência".

Tentando demonstrar que a tese da suficiência se adapta bem ao pensamento socrático, Vlastos (1994) cita trechos dos primeiros diálogos que parecem admiti-la como princípio. Em primeiro lugar, as seguintes passagens da Apologia: 
(a) Sócrates: [...] Pois saibais que, se me matardes, sendo eu um homem tal como eu digo ser, não ireis me ferir tanto quanto a vós próprios; pois nem Meleto nem Ânito poderiam me ferir; isto seria impossível, pois eu creio que não é o desejo divino que um homem melhor seja ferido por um pior [...]

(b) [diz Sócrates imediatamente a seguir]: Ele poderia, entretanto, talvez me matar ou me banir ou me privar dos direitos de cidadão; e talvez ele pense que poderia assim infligir a mim grandes danos, e outros podem pensar assim, mas não eu; eu penso que ele faz a si próprio um dano ainda maior ao fazer o que ele está fazendo agora - matar um homem injustamente (Platão, 1995, 30 c 5- d 5).

Segundo Vlastos (1994), ainda que em (a) Sócrates parecesse dizer que Meleto e Ânito não podem lhe causar um mal, e assim parecesse afirmar implicitamente que os bens não morais não têm qualquer papel quanto à felicidade, a passagem (b) indica que não era bem isso o que Sócrates queria dizer, pois aí ele não diz que seus acusadores não podem lhe causar nenhum mal, mas que eles não podem the causar nenhum grande mal. Entretanto, essa passagem não implica o que nos diz Vlastos (1994), pois, em (a), Sócrates afirma que Ânito e Meleto não Ihe podem causar nenhum mal moral, isto é, a injustiça e a maldade deles não podem torná-lo injusto; em (b), por outro lado, Sócrates está dizendo que, embora os dois considerem que matar, banir, retirar direitos sejam males, na verdade, o único e verdadeiro mal é o ato injusto, que causa dano somente àquele que o comete. Torturas, privações, perseguições e mortes não podem, mesmo implicando sofrimento físico ou a morte, tornar má e injusta uma vítima inocente - e, para Sócrates, como vimos acima, o bem consiste precisamente nisto: ser justo.

Vlastos (1994) tenta ainda amparar sua tese em outras duas passagens da Apologia:

Sócrates: [...] Se eu descobrir que ele não possui a virtude, mas a diz possuir, eu o repreenderei por atribuir o menor valor ao que tem o mais alto valor e dar o maior valor àquilo que é inferior (Platão, 1995, 29 e 5- 30 a 2).

Sócrates: [Eu os exorto] a não se importar por suas pessoas ou suas propriedades mais que pela perfeição de suas almas [...] pois a virtude não vem da riqueza, mas da virtude vem a riqueza e todas as outras coisas boas para o homem, tanto para o indivíduo quanto para o Estado (Platão, 1995, 30 a 8- b 4).

Tais passagens, segundo esse comentador, apoiam a tese da suficiência, pois nelas Sócrates não nos diz que os bens não morais não possuam qualquer valor, mas que seu valor é muito inferior à perfeição da alma, que é atingida quando a alma se torna virtuosa. E explica que isso é assim porque, com a virtude, os bens não morais tornam-se bens de fato para os homens. Outras passagens - por exemplo, na Apologia (Platão, 1995, 41 c 8- d 2), na República, (Platão, 1999, 335 c 1- 7) e no Górgias (Platão, 1991, 470 e 4- 11; 507 b 8- c 7) que parecem apoiar a tese da identidade se revelam compatíveis com a tese da suficiência pelos mesmos argumentos que acabamos de expor (Vlastos, 1994, p. 305- 308). Aqui se torna claro o equívoco que tanto Irwin (1995) quanto Vlastos (1994) cometem: ambos tendem a relacionar horizontalmente o bem moral socrático (a virtude) com os assim chamados bens não morais, esquecendo que a relação entre estes e aquele é, na verdade, vertical. Os bens não morais não são possíveis senão com a presença do único e verdadeiro bem: a virtude. Como tais bens não morais não são senão uma expressão ou uma consequência da virtude, eles são, na verdade, absolutamente indiferentes no que se refere ao grau de felicidade de alguém, pois o homem virtuoso invariavelmente 
age de modo virtuoso, tornando um bem toda situação em que vive e tudo que tiver diante de si. Em outras palavras: o homem justo usa com justiça tudo o que vier às suas mãos (e nisso consiste torná-las bens) e, na medida em que está no mundo, tem sempre diante de si coisas para bem usar e para tornar bens, pouco importando quais sejam. Os bens não morais, portanto, só podem existir em relação ao bem moral, a virtude ${ }^{3}$. Portanto, tais bens nada adicionam à felicidade, para a qual o único fator determinante é a virtude que determina a ação justa.

Vlastos (1994, p. 296) afirma, ainda, que a relação de identidade entre virtude e felicidade nos leva a teses paradoxais, pelas quais um homem virtuoso, mesmo sendo torturado e exposto aos mais terríveis sofrimentos físicos, é feliz na medida em que for virtuoso. Esse pensador argumenta que a opção de Sócrates pela tese da identidade seria absurda, pois, pelo princípio da identidade, "não haveria qualquer justificativa racional para escolher entre dois termos de uma alternativa que fossem igualmente compatíveis com a virtude" (Vlastos, 1994, p. 309).

No Górgias (Platão, 1991, 469 b 12- c 2), por exemplo, Sócrates, quando nos fala da escolha entre sofrer uma injustiça ou cometê-la, diz que não desejaria nem uma coisa nem outra, mas, se fosse forçado a escolher, preferiria sofrê-la. Ora, reflete Vlastos (1994), se Sócrates aceitasse a tese da identidade, Ihe seria absolutamente indiferente sofrer a injustiça. Porém, Sócrates nos diz que, entre o ato justo e o injusto, preferirá sempre o justo. Sofrer uma injustiça não é, em absoluto, algo justo. Não há, portanto, qualquer razão para Sócrates preferir tal coisa senão tendo diante de si a escolha entre cometer uma injustiça ou sofrê-la, quando, então, preferiria sofrê-la, não por ser isso justo, mas tão somente por não ser injusto como o seria cometer a injustiça. A questão é que, de fato, socraticamente falando, não há mesmo justificativa racional para escolher entre dois atos virtuosos, e isso não destrói, de forma alguma, o eudaimonismo de Sócrates, para quem o que importa é que a escolha entre o ato justo e o injusto se dê pelo justo, não levando em consideração tal situação em que dois atos justos fossem simultaneamente possíveis.

\section{A tese da identidade entre virtude e felicidade}

Como vimos, a imagem que Vlastos (1994) evoca contra a tese da identidade é a do homem virtuoso sendo torturado. Recoloquemos a questão de modo a esmiuçá-la: como tal homem pode ser feliz? E, ainda que seja feliz, como pode ser tão feliz quanto aquele que desfruta as belezas de um oásis? Para o senso comum, evidentemente, é impossível que um homem torturado seja feliz. A tese socrática, porém, é a de que a virtude habilita o homem a suportar a adversidade, mantendo-o justo, e, exatamente nisso, consiste a felicidade. Esse é o sentido do argumento do Eutidemo, que já apresentamos: a riqueza sem a sabedoria é má; com a sabedoria, é boa. O mesmo vale para a pobreza, para a saúde, para a doença, e para as demais coisas contrárias, pois algo é bom para o homem quando ele usa moralmente (isto significa: de modo justo) aquilo para o que necessita da virtude. Como já dissemos, o argumento do Eutidemo implica claramente que nada é intrinsecamente bom para o homem senão a virtude. Assim, primeiramente é preciso que separemos, por um lado, o bem e o mal e, por outro, o prazer e a dor. É claro que um homem, torturado, não sente prazer e que um homem, desfrutando um oásis, não sente dor. No entanto, isso não nos autoriza a dizer que o torturado seja menos feliz que o outro, socraticamente falando, em qualquer

${ }^{3}$ Bem como na medida em que mantêm essa relação. Cessando essa relação (isto é, deixando de ser governadas pelo homem justo) e caindo nas mãos do homem injusto, tornam-se males. 
medida que seja, pois a felicidade, para Sócrates, é uma questão moral, e não uma questão física.

Lembremos que o que concorre inicialmente para a felicidade do homem, em Sócrates, é a prática filosófica do autoexame: sem essa prática, a vida não vale a pena ser vivida, como é dito na Apologia (Platão, 1995, 38 a). E Sócrates prefere morrer a ter de parar de filosofar, como é dito na mesma Apologia (Platão, 1995, 29 c-d). Isso indica que a felicidade humana, para Sócrates, se inicia com este filosofar, que, para ele, significa examinar a si mesmo e, progressivamente, abandonar as falsas opiniões que guiam erradamente seus atos. São essas falsas opiniões que causam a infelicidade e não sofrimento físico ou prazer: como vimos pelo argumento do Eutidemo, o verdadeiro mal para o ser humano é a ignorância. E em que consistem essas falsas opiniões? Falsos valores atribuídos às coisas: que a riqueza seja, em si mesma, boa, que a saúde seja, em si mesma, boa, enfim, que algo exterior tenha valor por si. Sócrates, ao dizer que a sabedoria é o único bem, está afirmando que o bem do homem reside no seu próprio âmago e que é ele quem atribui (errada ou acertadamente) valor às coisas, a partir do seu entendimento do mundo. A atitude do ignorante, podemos asseverar, é fundamentalmente equivocada diante da realidade, pois tem falsas opiniões, falsas concepções sobre as coisas, e isso o leva a agir de uma forma injusta e imoral e, consequentemente, a ser infeliz.

Para Sócrates, a felicidade é progressivamente conquistada por meio do filosofar. Assim, a relação entre virtude e felicidade, em Sócrates, é uma relação de identidade, pois, por intermédio da virtude, o homem age de modo bom e belo e, por conseguinte, é feliz, não importando absolutamente qual matéria tem diante de si sobre a qual exerce a virtude. A posse da virtude é a felicidade para o homem, sua ausência, a infelicidade. Todo o resto é relativo a isso, nada acrescentado ou retirado no que se refere à felicidade, que significa possuir a virtude moral.

Vamos, por fim, analisar em que contexto é expresso o argumento do Protágoras que Irwin (1995) chama em seu auxílio na defesa da tese da instrumentalidade da virtude. Nesse diálogo, Sócrates faz a Protágoras a seguinte pergunta: concorda o sofista com a maioria, para quem há prazeres que são males e há dores que são bens? (Platão, 1990, 351c-d). Primeiramente, Protágoras diz concordar com a maioria (Platão, 1990, 351 d) e Sócrates introduz o que parece ser o cerne do argumento com um todo:

A opinião geralmente aceita é algo deste tipo: que [o conhecimento] não é forte nem capaz de guiar nem de governar [...] As pessoas pensam que, embora um homem tenha conhecimento, ele não é governado pelo conhecimento, mas por algo mais, ora pela paixão, ora pelo prazer, ora pela dor, ora pelo amor, e frequentemente pelo medo; consideram o conhecimento como um prisioneiro, que pode ser arrastado de lá para cá (Platão, 1990, 352 b-c).

Assim, o interesse primeiro de Sócrates no argumento em questão é provar que o conhecimento (episteme), outro nome que ele dá para a sabedoria (sophia) da qual trata no argumento do Eutidemo, "é algo nobre e capaz de governar o homem, e quem quer que aprenda o que é o bem e o que é o mal nunca será levado a agir por qualquer outra coisa senão como o conhecimento lhe ordena" (Platão, 1990, 352 c). Trata-se da célebre tese socrática, segundo a qual a virtude é puro conhecimento e não possui qualquer elemento não cognitivo. O que Sócrates quer provar, em sua argumentação, é que, mesmo aquele que considera o prazer como fim último, tem de reconhecer esse caráter diretor do conhecimento e que, 
portanto, é de seu interesse buscá-lo. Vejamos a continuação do argumento para saber se isto é mesmo como é dito.

Após Protágoras concordar com o que Sócrates dissera sobre o conhecimento, este argumenta que muitos creem que, embora saibam o que é o melhor, não o fazem em virtude do prazer, da dor e de outras paixões (Platão, 1990, 352 d). Considera, então, o que pode significar a expressão "ser vencido pelo prazer", por meio da qual muitos justificam não ter feito o que consideravam o melhor. Assim, a discussão sobre o prazer se dá em meio à discussão sobre a tese socrática do caráter cognitivo da virtude e de sua consequente negação da possibilidade da akrasía. Nesse contexto, deve ser compreendido o argumento de Sócrates sobre o prazer, apresentado na introdução (Platão, 1990, 353 b- 354 e). Isso é confirmado pelo próprio Sócrates, imediatamente depois desse argumento:

É suficiente para ti viver prazerosamente, sem dor? Se for, e se és incapaz de nos citar qualquer outro bem ou mal que não termine em dor ou prazer, ouve o que tenho a dizer. Afirmo que [...] o argumento se torna absurdo quando dizes que muitas vezes ocorre que um homem, sabendo que o mal é o mal, ainda assim o cometa, podendo evitá-lo (Platão, 1990, 354 e).

Torna-se clara a razão pela qual Sócrates partiu da hipótese da identificação do bem com o prazer e do mal com a dor: se o bem é o prazer, dizer não ter feito algo mau por ser vencido pelo prazer é o mesmo que dizer que fez o mal por ter sido vencido pelo bem, o que é absurdo (Platão, 1999, 354 b-c). Assim, Sócrates prova o seu ponto, qual seja, a impossibilidade da akrasía, tese segundo a qual o conhecimento sobre o que é o bem e o que é o mal determina a ação de quem o possui. Já citamos, imediatamente acima, a prova de que tais premissas sobre o bem e o prazer, o mal e a dor, são colocadas dialeticamente, como se Sócrates dissesse o seguinte: "É suficiente para ti viver prazerosamente, sem dor? Se for, e se és incapaz de nos citar qualquer outro bem ou mal que não termine em dor ou prazer, ouve o que tenho a dizer". Isto significa que Sócrates dirige seu argumento aos hedonistas. Por meio de sua dialética, reúne num só grupo, tanto aqueles do senso comum que consideram haver prazeres bons e maus, dores boas e más, quanto aqueles que simplesmente identificam o bem com o prazer, e a dor com o mal. Todos esses têm de aceitar que o conhecimento sobre o bem e o mal determina seus atos. Sócrates parte das crenças de seus interlocutores para provar que mesmo o hedonista não pode ser indiferente à virtude e à sabedoria.

Quanto ao próprio Sócrates, é claro que ele não se inclui entre os que acham que seja suficiente viver pelo prazer. Como já constatamos acima, Sócrates afirma, na Apologia, que se deve escolher sempre a ação justa, pois nada compensa a perda de um bem moral (Platão, 1995, 28 b 5- 9; 28 d6-10, 48 c6-d5). Afirma isso porque, como diz no Górgias (Platão, 1991, 507 c), as virtudes, quando possuídas por um homem, tornam-no bom, razão pela qual, como é dito no Criton (Platão, 1995, 48 b 11- c 2), em todas as ações, devemos seguir tão somente o critério da justiça, já que viver de modo justo equivale a bem viver. Agora, cumpre repetir a passagem da Apologia que citamos mais acima:

Sócrates: Manteremos ainda, sim ou não, que devemos conceder o mais alto valor não ao fato de viver (zen), mas ao fato de viver bem (eu zen)?

Criton: Manteremos isso.

Sócrates: E que viver bem e viver de modo justo (dikaios) e bom (kalos) são a mesma coisa? Manteremos isso ou não?

Criton: Nós o manteremos (Platão, 1995, 48 b 11- c 2). 


\section{Referências}

IRWIN, T. 1995. Plato's Ethics. New York, Garland, 536 p.

PLATÃO. 2002. Charmides. 79a ed., Londres, Harvard University Press, 512 p.

PLATÃO. 1995. Euthyphro. Apology. Crito. Phaedo. Phaedrus. $18^{\mathrm{a}}$ ed., Londres, Harvard University Press, 583 p.

PLATÃO. 1991. Lysis. Symposium, Gorgias. $10^{\mathrm{a}}$ ed., Londres, Harvard University Press, $536 \mathrm{p}$.

PLATÃO. 1990. Laches. Protagoras. Meno. Euthydemmus. $7^{\mathrm{a}}$ ed., Londres Harvard University Press, $508 \mathrm{p}$.

PLATÃO. 1999. Rebulic (books 1-5). $11^{\text {a }}$ ed., Londres Harvard University Press, 535 p.

VLASTOS, G. 1994. Socrate: Ironie et Philosophie Morale. Paris, Aubier, 357 p.

Submetido em: 21/06/2009

Aceito em: 23/09/2009 